\title{
Introduction to the Minitrack on Social-Technical Issues in Organizational Information Technologies
}

\author{
Michael Knight \\ Texas A\&M - Kingsville \\ michael.knight@tamuk.edu
}

\author{
Dragos Vieru \\ University of Québec \\ dragos.vieru@teluq.ca
}

\author{
Dawn Medlin \\ Appalachian State University \\ Medlinbd@appstate.edu
}

This minitrack focuses on information systems research areas impacting the intersection of humans and technology in an organizational context. Social issues related to organizational information technologies (IT) represents one of the most often discussed underpinnings in information systems research throughout the tenure of the IS field. Social issues are those research topics most aligned with the human factor in terms of information systems planning, development, implementation, and utilization.
This minitrack includes all aspects of social issues that are impacted by information technologies affecting organizations and inter-organizational structures. This would include the conceptualization of specific social issues and their associated constructs, empirical validation of social models, and case studies illustrating socialization success and failures. Key topics include:

- Organizational culture and identity

- Relationships

- Human interaction

- Diversity in the IT workforce. 